\title{
WHAT IS HOME? A COLLABORATIVE MULTIMODAL INQUIRY PROJECT BY TRANSNATIONAL YOUTH IN SOUTH PHILADELPHIA
}

FRIANNA GULTOM

MINGHUI LI

FREDERICK HIDAYAT

MARTIN PONCE

BORIS ZHININ

SINA WARD

OLIVIA VAZQUEZ
FAUSTINE GULTOM

JASMINE LIE

ODALYS PERALTA RIOS

DAVID SETIAWAN

YVONNE COLSON

ANKHI THAKURTA

LARRY NARRON
MARCO KOSASIH

CHRISTOPHER LORENZO

ERICK PEREZ

OWEN SETIAWAN

PATRICIA SENGBOUNPHENG CHLOE KANNAN

H. GERALD CAMPANO

\section{ABSTRACT}

KEYWORDS

home, sociocultural identity, youth inquiry

school students who are exploring issues of social justice, educational equity, and access in the context of a communitybased partnership between the University of Pennsylvania and the St. Thomas Aquinas community in South Philadelphia. The youth, who represent a range of racial, linguistic, and cultural backgrounds, each explored what "home" meant to them through multiple rounds of writing and revision.

Then, after reflecting further through art projects and group conversations, they collaboratively assembled these final compositions with their peers.

\section{NOTE ON THE USE OF THE TERM "TRANSNATIONAL YOUTH"} We echo uses of this term in recent scholarship to refer to those with linguistic, political, spiritual, and cultural ties beyond the boundaries of the nation-state (Ghiso, 2016; Shirazi, 2018). Ghiso (2016) notes, for instance, some of the salient features in the lives of transnational youth: "multiple national affiliations, fluid migration histories, global technological networks, and plural identities" (p. 2). 


\section{INQUIRIES INTO HOME: INTRODUCING THE AQUINAS CENTER YOUTH GROUP} What is home? The poem and artwork in this contribution reflect perspectives on this essential question from the Aquinas Youth Group, a collective of middle school and high school students from the University of Pennsylvania-St. Thomas Aquinas community research partnership. Representing a range of backgrounds, these youth work across racial, linguistic, and cultural boundaries to explore issues related to educational equity and access. The larger "home" of the group is The Aquinas Center, a faith-based, multilingual community space in South Philadelphia that "provides opportunities for fostering non-dominant social arrangements and advocacy on behalf of immigrant rights and educational justice" (Campano, Ghiso, \& Welch, 2016, p. 19). Offering immigrant legal services, English classes, workshops about navigating the college admissions process, and other resources, the Center supports generations of adults and youth from Vietnamese, Cambodian, Filipino/a, Indonesian, various Latin American and Sudanese communities in a time characterized by "social and economic precarity due to neoliberal policies that have eroded affordable housing, access to education, and employment opportunities" (Campano et al., 2016, p.19). The University of Pennsylvania has collaborated with Center members for nearly a decade to confront these inequities through co-generated research inquiries and communal action.

During most Saturdays in the 2018-2019 academic year, approximately 15 youth from the broader St. Thomas Aquinas (STA) community gathered in one of the Center's basement classrooms to extend the work of the partnership. Brightening the space with laughter, conversations, questions, and ideas, they worked with us: two doctoral students at Penn studying the interconnections of literacy and power in the field of education, a master's student in the literacy program, and an activist-educator. Our group assumes a sociocultural stance towards literacy that is rooted in theoretical traditions, including New Literacy Studies (Gee, 1990; Street, 1995; Barton, Hamilton, \& Ivanič, 2000). Moving past narrow notions of "text reception and production" within regimented learning contexts (Skerrett \& Bomer, 2011, p. 314), these approaches attend instead to the diverse ways that individuals make meaning in a world shaped by "hierarchies of power and ideologies about whose knowledge counts" (Campano, Ghiso, \& Sanchez, 2013 p. 100). We are also anchored by critical pedagogies (Freire, 1987) and the principles of Youth Participatory Action Research (YPAR) - these connect to destabilizing the traditional hierarchies between "teachers" and "learners," and helping 
youth realize their potential as knowledge producers (Mirra, Garcia, \& Morrell, 2016, p. 2). Our practices and approaches, then, reflect expansive notions of what research is and who is positioned to produce it. Guided largely by the vision and

\section{Our practices and approaches reflect expansive notions of what research is and who is positioned to produce it.}

interests of our youth participants, we endeavor to make our work as anti-hegemonic and community-facing as possible.

Over pepperoni pizzas and tacos al pastor, members of the Youth Group mobilized their sociocultural identities and multiple literacies to interrogate issues connected to equity, education, culture, and society more broadly. On the subject of education in particular, their topics of interest this year have ranged from course tracking, what makes sites of learning feel safe or unsafe, the school-to-prison pipeline, representations of diversity in curricula, the unequal distribution of resources across city schools, and the presence of security in learning spaces. Youth were critical throughout this process of what made various environments feel more or less supportiveJasmine, one of the participants, said that she experienced a "fear of being judged" at middle school for her clothing choices, linguistic practices, and food. This feeling contrasted with her perspectives towards home, a space where she felt freer: "At home, you can use whatever language you want, and no one will really judge you. You can wear the most comfortable thing that looks the least appealing, and nobody would care. You can eat anything," she said. Marco, a high school student, equated home with protection. As he observed, "Anything else outside the home, we feel unprotected, and danger could happen anywhere." Reflecting on how schools could be more safe and welcoming, he emphasized the benefits of nurturing meaningful relationships with other students and the staff over typical security measures: "To have school safe, we would need to have people we know there-friends, family, people we have connections with. Yeah sure there's metal detectors that can look through belongings and detect weapons such as guns and knives, but human connection itself makes the brain think this is safe; people with good connections make us feel safe," he said.

Most recently, we have begun to investigate the steps of the research process to support youth as they utilize their epistemic privilege (Campano, 2007; Moya, 2002) to conduct inquiries about the particular iterations of systemic inequality they confront in their own lives. This concept, emerging from realist theory, is premised on the assumption that "minoritized social locations provide unique vantage points from which 
to understand the world and how it produces inequality" (Campano et al., 2013, p. 102). The students also have what anthropologist Jayne Ifekwunigwe (1999) has called "scattered belongings," or multiple rhizomatic connections across the world. We have come to realize as an inquiry community that addressing issues of social justice, such as educational equity and access, is an important part of home-making in their immediate physical localities, which are often transnational local spaces (Ghiso, 2016).

\section{THE PROCESS: A MULTIMODAL INQUIRY IN TO HOME}

Though all members of the Aquinas Youth Group live in Philadelphia, most sustain active ties to numerous cultures, languages, communities, and nations. Following the lead of scholars who cite the affordances of making meaning through various communicative means (Vasudevan, 2010, Ghiso \& Low, 2013), we used a multimodal approach to explore the concept of home. Our group inquiry emphasized three modes - verbal, written, and visual - over the span of multiple sessions. During our first inquiry meeting, we began with brainstorms that allowed youth participants to tap into their background knowledge. What, we asked them, did they consider home? All group members responded to that prompt in five lines or fewer. Then, they individually explored the concept of home through visual media. Youth used various materials - colored pencils, magazine cutouts, markers, and more-during this part of the process.

After working on their artistic representations of home, the youth and facilitators sat together in a circle to discuss the themes that emerged from their pieces. Diverse ideas surfaced during that conversation-most students, for example, drew on experiences with their immediate families in South Philadelphia to emphasize how cultural elements such as the food, music, and practices of their transnational, multigenerational networks featured in their conceptions of home. Olivia, a former

Students drew on experiences with their immediate families in South Philadelphia to emphasize how cultural elements such as the food, music, and practices of their transnational, multigenerational networks featured in their conceptions of home. community organizer of

a Latinx immigrant rights organization, included an image of concha bread in her composition-food, she said, represents a connection between home and her Mexican roots.

Others focused on the affective dimensions of the concept: Frederick, a ninth-grade Indonesian American student, painted a sunset to symbolize the warmth and comfort he associates 
with home. He observed that "home is a community where you feel supported." Still others meditated on how their ideas about home connect to the broader legacies of ancient cultures: Odalys, a junior in high school and of Mexican descent, sketched a yellow pyramid that represented the "precolonial past" of her family. In her final piece, this ancient image is juxtaposed with "modern" urban images, suggesting an interplay of space, time, and ongoing legacies of coloniality in her personal vision of home.

After students shared these compositions, they went back and revised their initial lines of poetry. Before the end of the fall semester, youth members worked in two different teams to piece their individual contributions into a collective composition. One group chose to focus on commonalities that resonated across these particular poems, while the other chose to capture the distinctions present within the collective. After these revisions, we took the poem a step further-after reading several model poems together to develop a deeper sense of poetic form and craft, the youth returned to collectively revise their piece one last time. During this session, they took artistic risks with the language of their composition and worked to incorporate more details from their sociocultural identities and histories.

The collaborative result is a braiding of what home is for a group of transnational youth in the United States, and the many places where it can be found. We use the term "homemaking" to emphasize how home is not a given, but something that is created through individual and collective agency. This ties to feminist and decolonial conceptions of homes as sites of both refuge and resistance for the oppressed. In her discussion

We use the term 'home-making' to emphasize how home is not a given, but something that is created through individual and collective agency.

of the importance of domestic spaces for Black families, for example, bell hooks (1990) invokes the concept of homeplace. Observing that the lives and labor of Black women were undermined in a heteropatriarchal, white supremacist social order, she foregrounds how these individuals transformed homes into "spaces of care and nurturance in the face of the brutal harsh reality of racist oppression, of sexist domination" (p. 384). hooks thus positions the making of homeplace as a subversive political act that facilitated the "renewal and selfrecovery" of those most harmed by systemic oppression ( $p$. 389).

In our present political climate, when people are invoking national homelands to justify virulent xenophobia and racialized violence, the efforts of youth to imagine new 
homes in South Philadelphia that center both multiplicity and difference evoke these earlier constructions of homeplace.

The multimodal artifacts from our inquiry community reflect how members of this group uplift themselves and each other, resisting the indignities of the "public world' in the process (hooks, 1990, p. 384).
The multimodal artifacts from our inquiry community reflect how members of this group uplift themselves and each other, resisting the indignities of the "public world" in the process (hooks, 1990, p.

384). They will be used to help ground our coalitional work as a qualitative research team moving forward.

THE POEM: HOME

Home dangles between reservations, continents, cities, countries, and towns.

A place that sings within the crevices of our past, present, and future.

\section{A foreign soldier}

In lines,

Being told what to do,

And how to act

School isn't home

At home I don't have to act a certain way;

I can be me and not be judged

Take me to the place where my seed was crafted, and blew into another country.

Take me to Jakarta, Bogor, and Bali,

With all the shells that wash up in Indonesia,

Take me to the grey moss stumbling upon the cracks and stone.

Take me to the place that smells like fried chicken and happiness.

A setting to which we would forever return because of the memories and experiences that we have made there.

Home is where I can rest and have freedom all upheld by the sweat, blood, and tears of our ancestors.

Whether it is then or now, we carry our home in the mind and in the heart.

Home is where there is an abundance of love and compassion, Where one can be oneself without the fear of judgement, Where smiles and laughs are shared with the people we love, Where the "ampao" is given to the young, and the large family 
gathers under the Cross hanging on the high wall; the same as the previous years.

Where hatred does not exist.

Home is more than just a place we live in, Home is all the things we love and care for. Home is where I am, what I love, and what I am doing. Home is where everyone is together.

Home is warm conversations and storytelling:

A home where beautiful beaches are filled with beautiful batiks and palatable perkedel.

A home where I hear oil crackling on the stove and smell chorizo with warm tortillas.

A home where I wake up on Sundays to the sound of my native tongue singing to Jesus.

A home where I watch little kids with radiant smiles waiting for their turn to hit the piñata.

Home travels with you.

It's never just one place.

Home will always sing alongside family and friends.

Home is comfortable.

Home is who I am because I am home. 


\section{THE ARTWORK}

How does the artwork connect to the poem? The following are reflections on both the visual projects and the process of collaborative writing from the students:

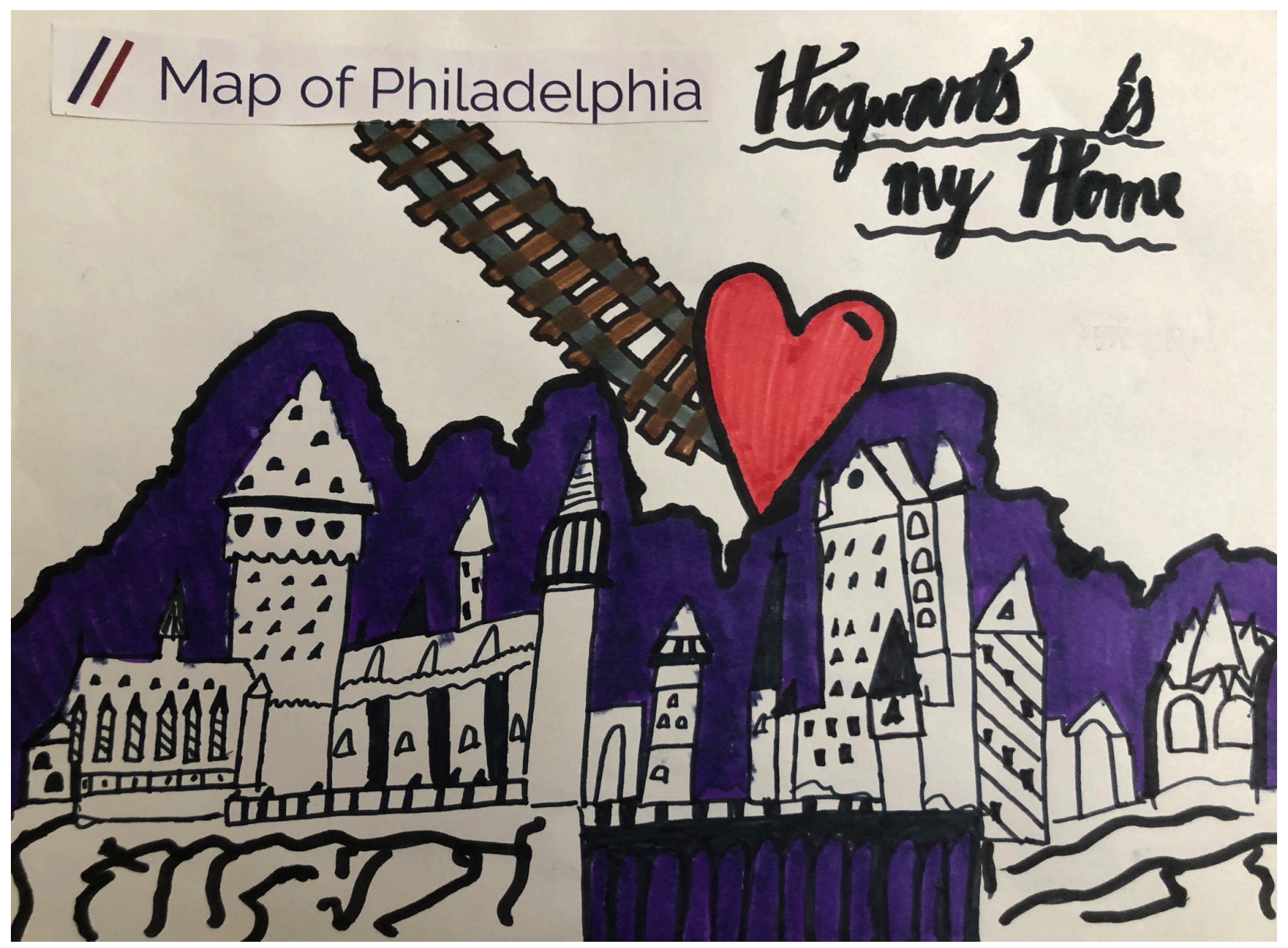

1. Owen Setiawan:

Just like at Hogwarts, everyone is welcoming to each other, like in my own home. We all can be ourselves, like how everyone can be who they are at Hogwarts! 


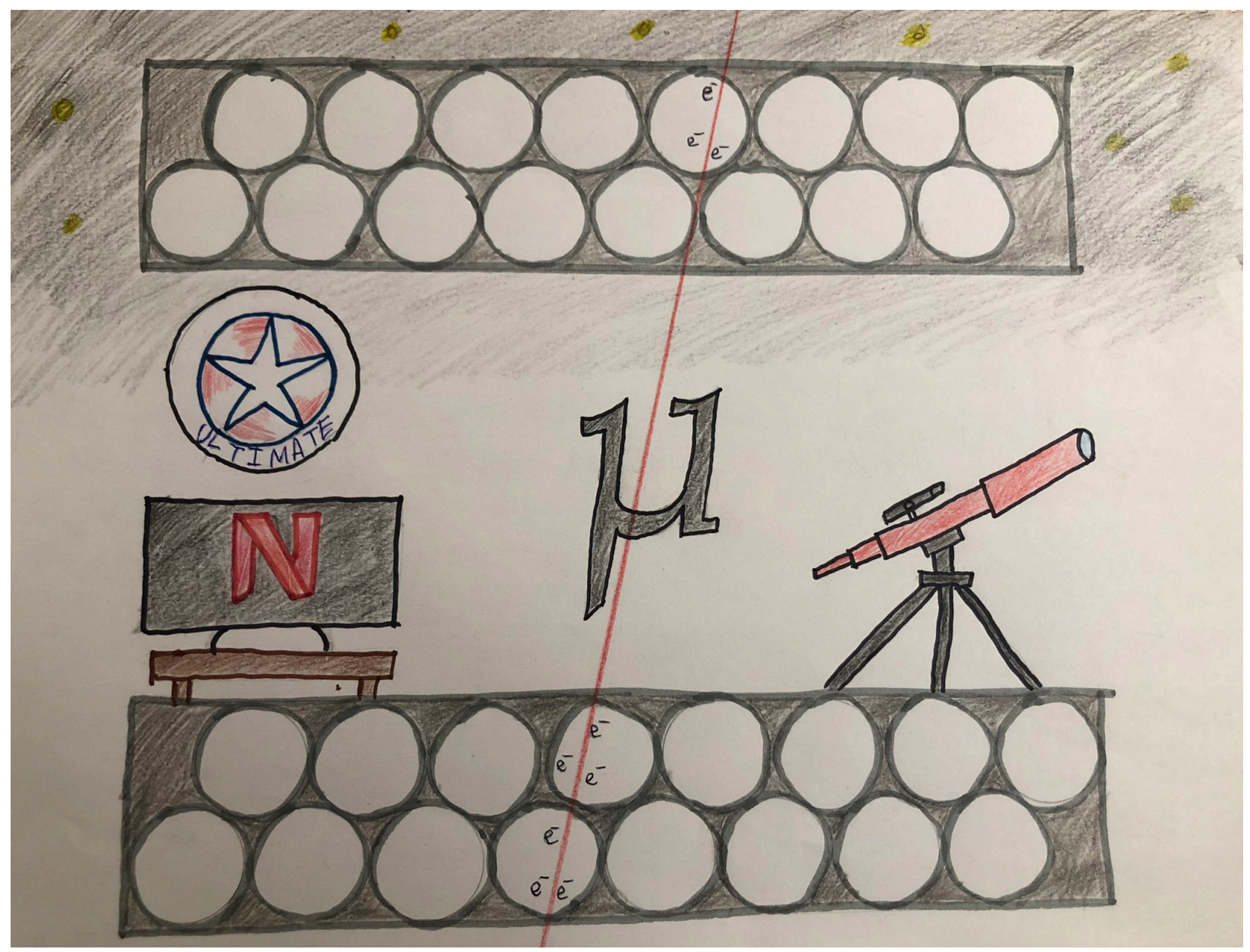

\section{David Setiawan:}

My idea of home is some place where all my interests come together. With this said, I drew my piece with the idea of combining my four main interests and hobbies: Netflix, Ultimate Frisbee, Astronomy, and Physics. The things I drew are things that would make me feel comfortable and content in a home.

Our poem is based on our beliefs of what home is. Drawing the piece allowed me to really think about what I wanted in a home, since I had never really thought about it before. After I drew the piece, I "connected the dots" and figured out that all the things I drew were relating to the central idea that, as I said previously, my home would be a place where my interests came together. 


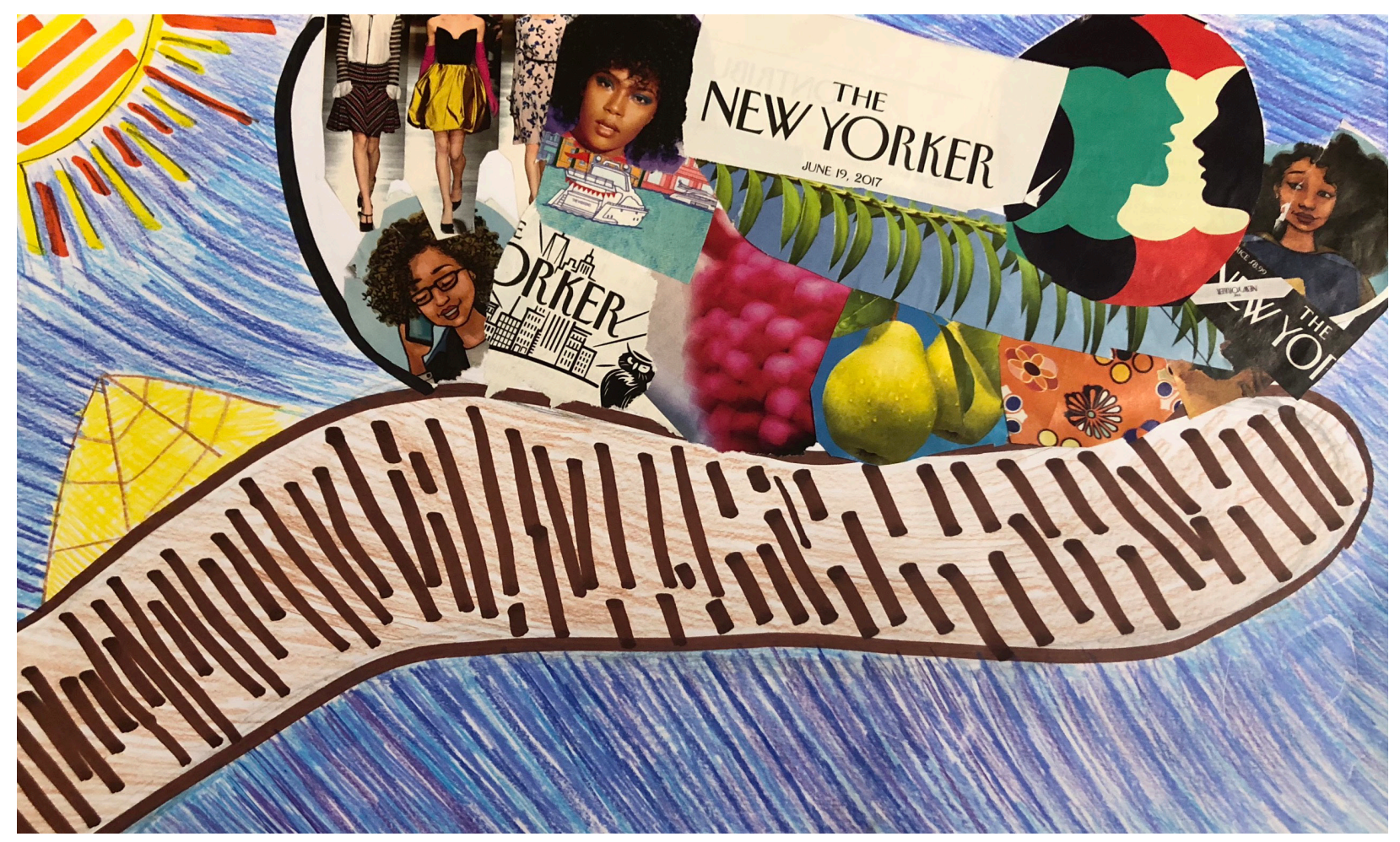

\section{Odalys Perelta Rios:}

My personal thought of home as I did my artwork was mainly support. My culture is the fundamental support I grew up with all my life. It strongly shapes who I am. This is why I attempted to draw a hand as a sign of support. I added color and brightness because that's what my culture is to me; my culture enlightens me physically and mentally. As I chose several images, I added parts of this new culture I am a part of -the "Chicana," the Americanized Latina. I added to this mixture through the words "New York."

I think this artwork contributes to the main components of our group project because we describe our home as this safe place where we feel comfortable with our identities, with our culture, with our skin and flavors, where we try to push away all the systemic ideologies the outside word imposes on us. It's that fundamental support of home and culture through which we embrace the power of self-identity. Home is the reflection of the beauty of our values, traditions, and ancestors that guide us and that we carry on our backs everywhere we go as a reminder of the empowerment and resistance we possess in our history, in our roots. 


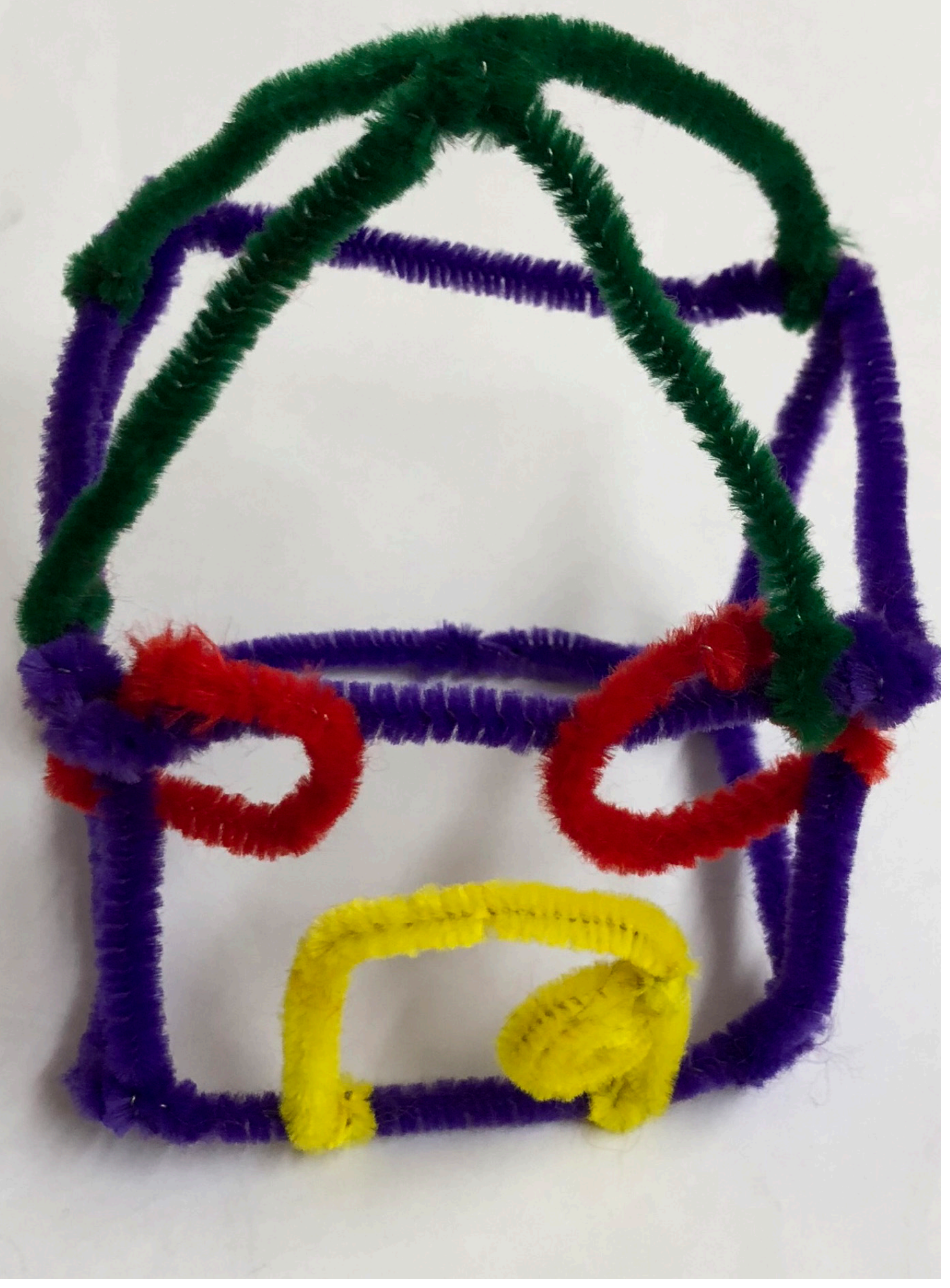

4. Erick Perez:

It's home. A physical object, and so that is home to me. 


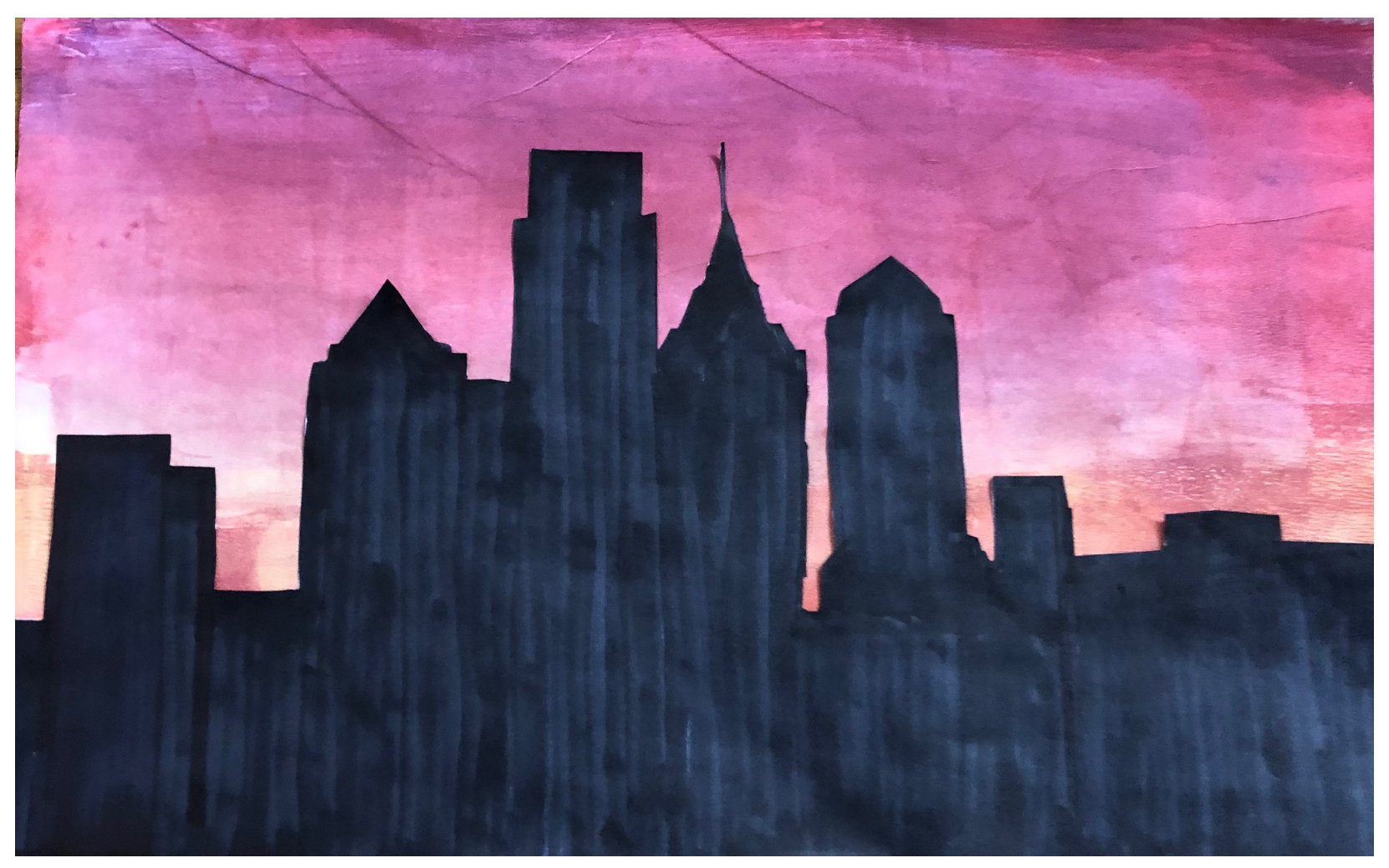

5. Frederick Hidayat:

In my work of art, I included a sunset with a silhouette of the Philadelphia skyline. I chose to use a sunset as the background, as opposed to a normal blue sky, because sunsets include all of the warm colors. To me, home makes me feel warm inside, and the sunset brings the warm vibe to the piece. 


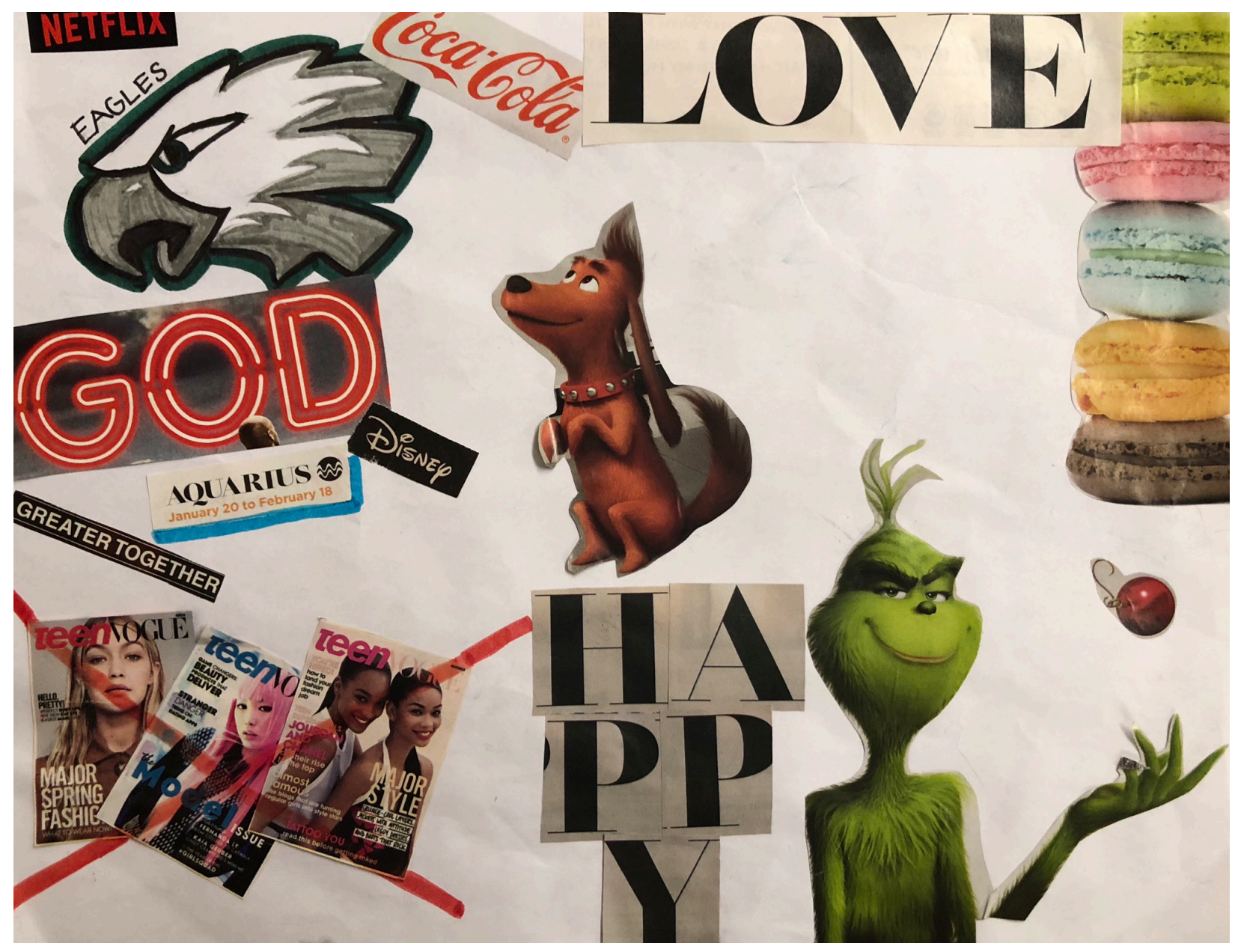

6. Faustine Gultom:

Home to me is my happy place. I don't have to look the best to still be loved by my family. Home is where my dog is and where family come to spend the holidays together. 


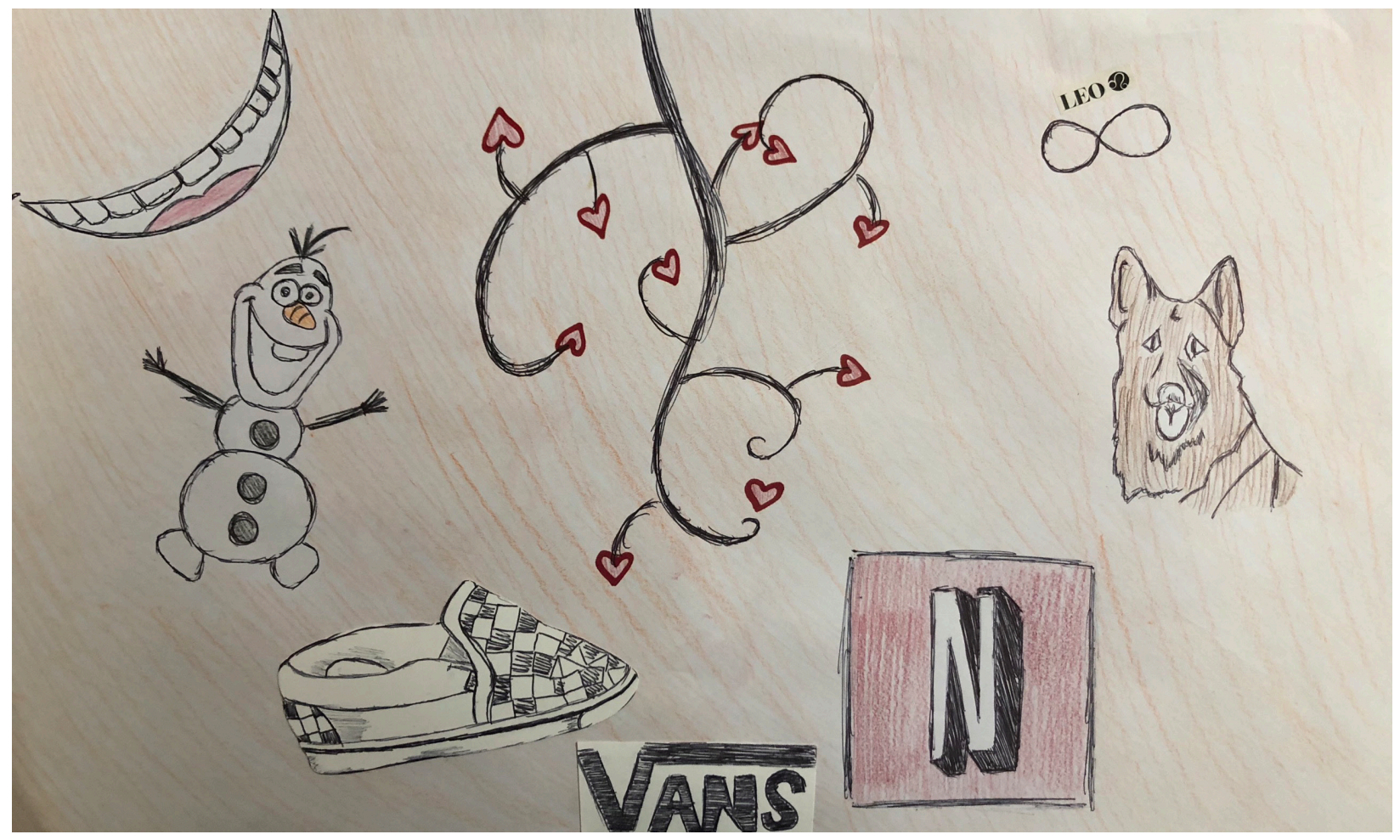

\section{Frianna Gultom:}

My response to my artwork is that love grows more and more each day by being around my family members and friends. I drew some miscellaneous things that remind me of home. I think the artwork that I made contributes to the group writing process about home because home is not only a place but can also be a person-my love tree reminds me of that. 


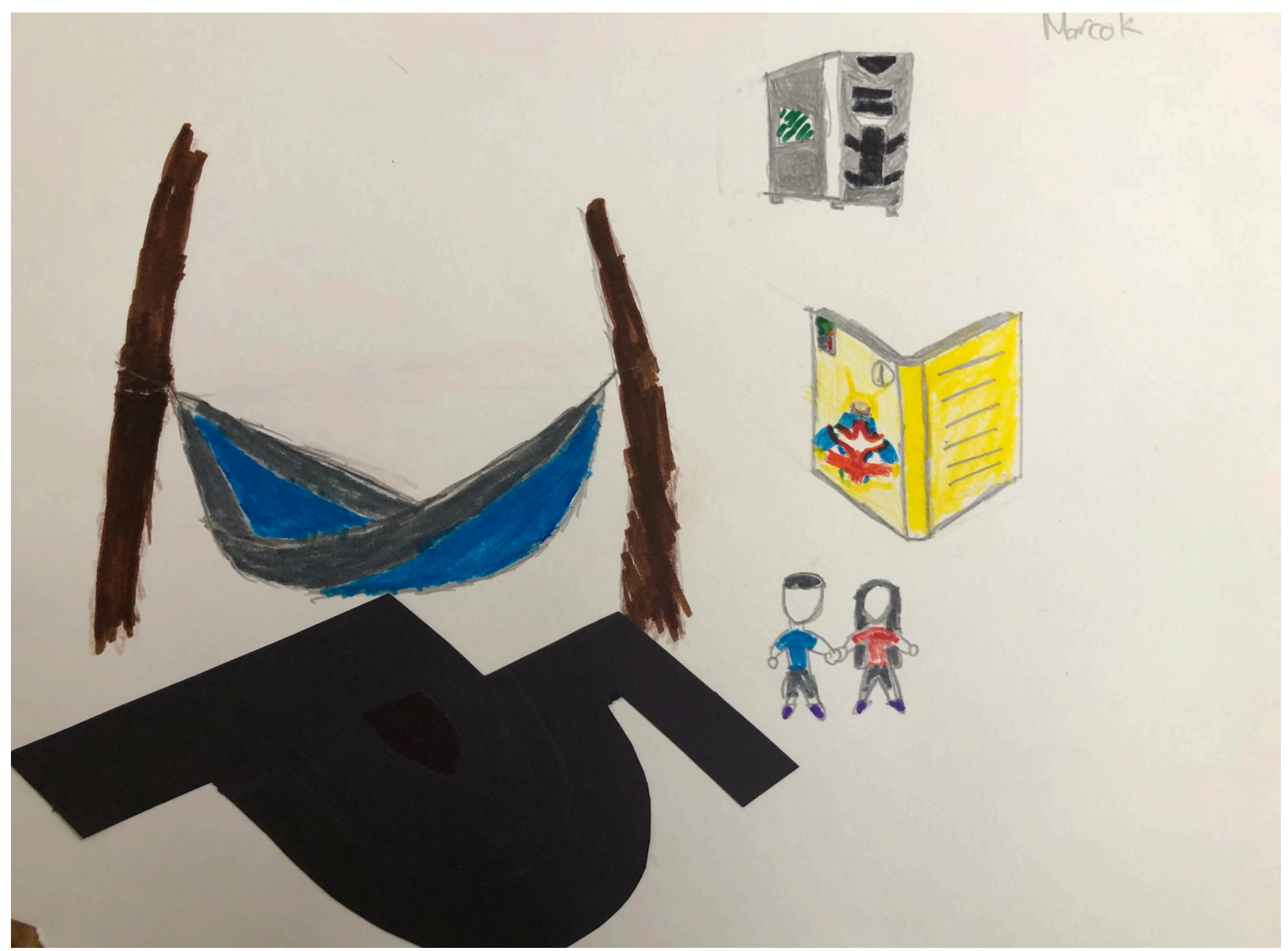

\section{Marco Kosasih:}

My artwork reflects my bedroom and the things that are happening in my home. The hammock is the bed that I wish to have-standing next to the comic that I always read while on it. The computer that I use every day to complete my assignments and all the college applications that I am working on are included. The two people holding hands are my parents, whom I love, always supporting me through rough times. 


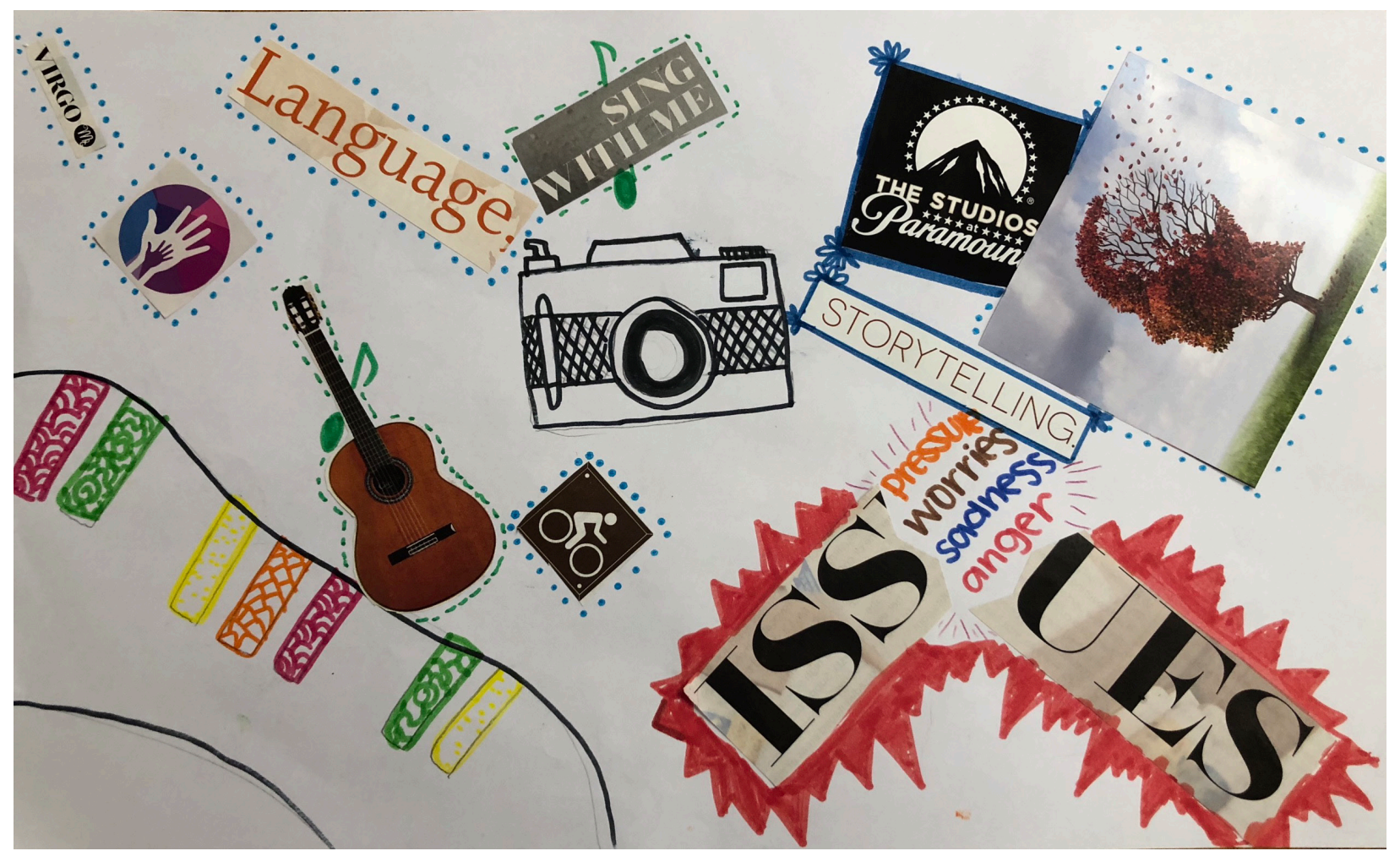

9. Jasmine Lie:

I think my artwork reflects my personal idea of home because it shows memories, represented through the camera, and the idea of being able to talk about issues without being judged or put down. Since home reminds me of a lot of music, there are several music-related things within the art piece. This artwork helped me write my poem, because it tells me that home is really comfortable and that many places can be called home. 


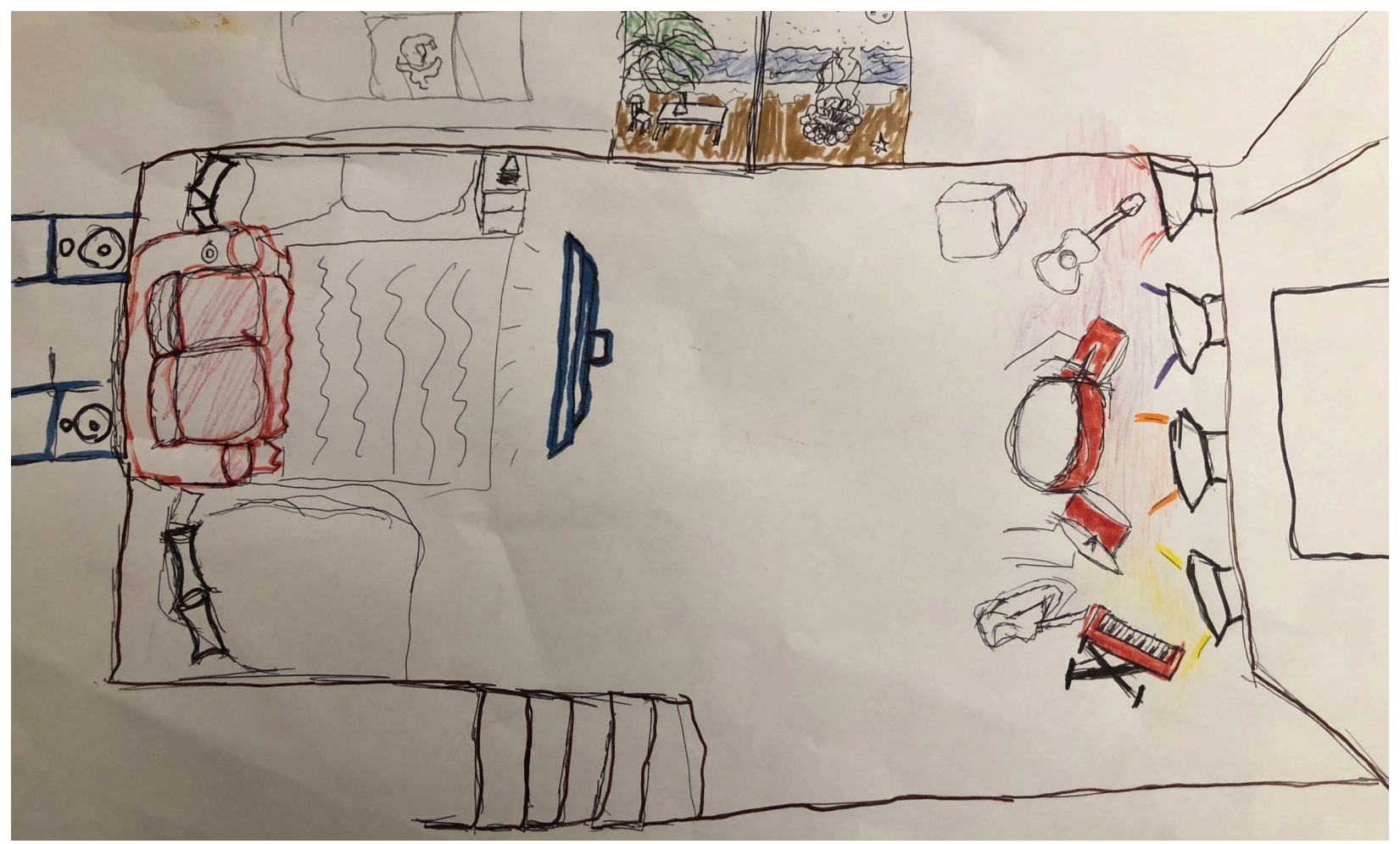

10. Christopher Lorenzo:

So basically, to me, home is me being accepted for who I am. I am appreciated and respected-which is what my friends and family do. I am able to communicate with the people I am with. My friends and family are able to understand me. My family knows what I like, what I don't like. They accept it. My friends know where I'm from, that I speak two languages. They accept me, and everything that comes with me, like my culture and background, for example. I feel like I belong. That's what home is to me.

Most of the things in my pictures are objects in a room. This to me is my safe space. I bunched up all the things I like into one room. The couch and bed on the sides show how I like to relax. But I also wanted to make the piece reflect how home to me is comfortable; I am comfortable at home. Music is a big part of me-my family and I listen to music all the time, as do my friends and I. The instruments are there because I know how to play a few. They make me feel good, just like music overall makes me feel good. On the wall, there is a Mexican flag, which is there to represent me. On the outside, there is a fire and tables with chairs. My family and friends often get together to hang out. My family hosts get-togethers and we eat and enjoy the moment. My friends and I make plans, hang out, and have a good time. 


\section{REFLECTIONS AND LOOKING FORWAR D}

Though our inquiry about home reflects the diverse ways that Youth Group members envision the subject, it also unearths a commonality across the compositions - that home is neither a fixed location nor singular idea, but rather a dynamic hybrid of the people, concepts, practices, literacies, artifacts, and histories with whom and with which individuals nurture deep connections. Some compositions contain elements both aspirational and fantastic-Hogwarts Castle from Harry Potter and the city of Philadelphia are juxtaposed in Owen's piece. Distant places and times also emerge from these artifacts; gesturing to migrational journeys taken by earlier generations of Youth Group families from nations such as Indonesia and Mexico, the work remixes the local and the global to present visions of home that are simultaneously immediate and expansive in scope (Vasudevan, 2010). Emotionally, home is associated with feelings of happiness, nourishment, and protection; this is contrasted with affective responses to other spaces and concepts, such as school or the outside world.

Our inquiry together, in short, envisions new possibilities for imagining and building home. It aligns with the broader ambitions of the Aquinas intergenerational community in fundamental ways - much of the work that members have done and continue to do is fueled by a desire to make society more hospitable and, indeed, homelike for marginalized populations. In ways both small and sweeping, these efforts have historically created nourishing spaces for "a meaningful community of resistance" in South Philadelphia (hooks, 1990, p. 388). We facilitators will honor these legacies of solidarity and care by supporting the youth members with their research inquiries in the months ahead; to do so, we hope to add to the foundations on which so many of their multimodal projects rest-love, community, inquiry, and imagination. 


\section{A C R NOW LEDGM E N T S}

There are many people we must acknowledge for their invaluable contributions. We would like to thank Dr. Bethany Welch, Director of the Aquinas Center, for her support of the Youth Group; the many families of the University of Pennsylvania-St. Thomas Aquinas partnership for their endless love; and Dr. María Paula Ghiso of Teachers College, Columbia University, for her critical and detailed feedback during many rounds of writing and revising. We are grateful to all of these individuals for their enduring belief in the work of the partnership.

\section{AUTHOR BIOS YOUTH PARTICIPANTS}

FRIANNA GULTOM

FAUSTINE GULTOM

MARCO KOSASIH

MINGHUI LI

JASMINE LIE

CHRISTOPHER LORENZO

FREDERICK HIDAYAT

ODALYS PERALTA RIOS

ERICK PEREZ

MARTIN PONCE

DAVID SETIAWAN

OWEN SETIAWAN

BORIS ZHININ

PATRICIA

SENGBOUNPHENG

YVONNE COLSON

SINA WARD
Frianna Gultom is a senior in high school. She's into art making/designing and thrifting.

Faustine Gultom is a sixth grader who is also a member of the Aquinas Center community.

Marco Kosasih is a senior in high school. He is into computers and loves to wear polos.

Minghui Li is a student in Philadelphia and member of the St. Thomas Aquinas community.

Jasmine Lie is a seventh grader in Philadelphia. Jasmine likes to swim and loves jellyfish.

Christopher Lorenzo is a junior in high school. He enjoys playing and listening to music and hanging out with his friends and family.

Frederick Hidayat is a ninth grader. He enjoys listening to music and socializing with his friends.

Odalys Peralta Rios is a student in Philadelphia and member of the St.

Thomas Aquinas community.

Erick Perez is a sophomore in high school. He's into music.

Martin Ponce is a junior in high school. He's into soccer and spending time with friends and family.

David Setiawan is a senior in high school. He's into physics and playing Ultimate Frisbee.

Owen Setiawan is an eighth grader in Philadelphia. Owen likes to write and loves Harry Potter.

Boris Zhinin is a student in Philadelphia and member of the St. Thomas Aquinas community.

Patricia Sengbounpheng is a high school senior.

Yvonne Colson is a senior at Neumann Goretti High School.

Sina Ward is a tenth grader at Mastery Charter. 


\section{FACILITATORS}

ANKHI THARURTA

CHLOE RANNAN

OLIVIA VAZQUEZ

LARRY NARRON

H. GERALD CAMPANO
Ankhi Thakurta is a doctoral student in the Reading/Writing/Literacy division at the University of Pennsylvania.

Chloe Kannan is a doctoral student in the Reading/Writing/Literacy division at the University of Pennsylvania.

Olivia Vazquez is an activist-educator.

Larry Narron is a master's student in the Reading/Writing/Literacy division at the University of Pennsylvania.

H. Gerald Campano is a professor of education and Chair of the Literacy, Culture, and International Education (LCIE) Division at the Graduate School of Education at the University of Pennsylvania. 
R E F E R E N C E S

Barton, D., Hamilton, M., \& Ivanic, R. (2000). Situated literacies: Reading and writing in context. New York, NY: Routledge.

Campano, G. (2007). Immigrant students and literacy: Reading, writing, and remembering. New York, NY: Teachers College Press.

Campano, G., Ghiso, M. P., \& Welch, B. J. (2016). Partnering with immigrant communities: action through literacy. New York, NY: Teachers College Press.

Freire, P. (1987). Chapter 2: The importance of the act of reading. In P. Freire \& D. Macedo, Literacy: Reading the word and the world (pp. 29-36). South Hadley, MA: Bergin and Garvey.

Gee, J. P. (1990). Social linguistics and literacies: Ideology in discourse. Philadelphia, PA: Falmer Press.

Ghiso, M. P. (2016). The laundromat as the transnational local: Young children's literacies of interdependence. Teachers College Record, 118(1), 1- 46.

Ghiso, M. P. \& Low, D. (2013). Students surfacing micronarratives of immigration through multimodal literacies. Literacy, 47(1), 26-34.

hooks, b. (1990). "Homeplace (a site of resistance)." In b. hooks, Yearning: Race, gender, and cultural politics (pp. 383-390). Boston, MA: South End Press.

Ifekwunigwe, J. (1999). Scattered belongings: Cultural paradoxes of "race," nation, and gender. New York, NY: Routledge.

Mirra, N., Garcia, A., \& Morrell, E. (2016). Doing youth participatory action research: transforming inquiry with researchers, educators, and students. New York, NY: Routledge.

Moya, P. (2002). Learning from experience: Minority identities, multicultural struggles. Berkeley: University of California Press.

Shirazi, R. (2018). Decentering Americanness: Transnational youth experiences of recognition and belonging in two U.S. high schools. Anthropology \& Education Quarterly, 49(2), 111-128.

Skerrett, A., \& Bomer, R. (2011). Borderzones in adolescents' literacy practices: Connecting out-of-school literacies to the reading curriculum. Urban Education, 46(6), 12561279.

Street, B. (1995). Social literacies: Critical approaches to literacy in development, ethnography, and education. London: Longman.

Vasudevan, L., Schultz, K., \& Bateman, J. (2010). Rethinking composing in a digital age: Authoring literate identities through multimodal storytelling. Written Communication, 27(4), 442-468. 